\title{
Ocorrência de vírus em cultivos de feijoeiro-caupi no Sertão da Paraíba
}

\author{
Aurivan Soares de Freitas ${ }^{1}$, Márcia Aparecida Cezar ${ }^{1}$, Márcia Michelle de Queiróz Ambrósio², Ana Kelly \\ Firmino da Silva ${ }^{3}$, Maria do Livramento Aragão ${ }^{3}$ \& José Albérsio de Araújo Lima ${ }^{3}$
}

${ }^{1}$ Unidade Acadêmica de Ciências Agrárias, Faculdade de Agronomia, Universidade Federal de Campina Grande, 58840000, Pombal, PB, Brasil; ${ }^{2}$ Departamento de Ciências Vegetais, Faculdade de Agronomia, Universidade Federal Rural do Semiárido, 59625-900, Mossoró, RN, Brasil; ${ }^{3}$ Departamento de Fitotecnia, Faculdade de Agronomia, Universidade Federal do Ceará, 60451-970, Fortaleza, CE, Brasil

Autor para correspondência: Márcia Aparecida Cezar, e-mail: macezar@ccta.ufcg.edu.br

\section{RESUMO}

Visando verificar a ocorrência de vírus em cultivos de feijoeiro-caupi (Vigna unguiculata), foram realizadas visitas de inspeção a campos de produção dos municípios de Bom Sucesso, Paulista e Pombal, no estado da Paraíba, durante os meses de agosto a dezembro de 2009 e de fevereiro a maio de 2010. Amostras foliares com sintomas típicos de mosaico e deformação foliar foram coletadas e analisadas por "enzyme linked immunosorbent assay" (ELISA) indireto contra anti-soros específicos para Cowpea aphid-borne mosaic virus (CABMV) e Cucumber mosaic virus (CMV) e por dupla difusão em ágar contra anti-soro para Cowpea severe mosaic virus (CPSMV). Cinco amostras coletadas com sintomas de mosaico dourado no município de Pombal na época chuvosa foram submetidas à detecção molecular por meio de "Polymerase Chain Reaction" (PCR) para Begomovirus. A ocorrência de CPSMV e CABMV foi observada nos campos de produção dos três municípios visitados nas duas épocas de cultivo analisadas, em infecções simples e mistas. A presença de vírus do gênero Begomovirus foi confirmada em amostras foliares com sintomas de mosaico dourado. Entretanto, estudos adicionais serão necessários para a identificação da espécie. CMV não foi detectado em nenhum dos municípios analisados.

Palavras-chave: Begomovirus, Comovirus, Cucumovirus, Potyvirus, detecção sorológica.

\begin{abstract}
Occurrence of viruses in cowpea in the State of Paraíba, Brazil

Visiting inspections were made in cowpea (Vigna unguiculata) fields in the counties Bom Sucesso, Paulista and Pombal, in the State of Paraíba, Brazil, during the period of August to December 2009 and February to May 2010 in order to verify the occurrence of virus. Leaf samples with typical symptoms of mosaic and leaf distortion were collected and tested by indirect "Enzyme linked immunosorbent assay" (ELISA) against antisera specific to Cowpea aphid-borne mosaic virus (CABMV) and Cucumber mosaic virus (CMV), and by double immune diffusion test to Cowpea severe mosaic virus (CPSMV) antiserum. Five samples collected in Pombal county during the rainy season showing golden mosaic were tested by Polymerase Chain Reaction (PCR) with primers to virus from the genus Begomovirus. The occurrence of CPSMV and CABMV was observed in the three counties in the two growing seasons in single and mixed infections. The presence of a virus from the genus Begomovirus was confirmed in leaf samples with golden mosaic, but further studies will be required to identify the species involved. The presence of CMV was not detected in any of the counties.
\end{abstract}

Key words: Begomovirus, Comovirus, Cucumovirus, Potyvirus, serological detection.

O caupi [Vigna unguiculata (L.) Walp., subspecies unguiculata], também conhecido como feijão-de-corda, é produzido predominantemente nas regiões Norte e Nordeste do Brasil, onde é utilizado, principalmente, como alimento básico de elevado valor protéico pela população de baixa renda, representando a principal cultura de subsistência (Pio-Ribeiro et al., 2005).

No estado da Paraíba, o feijoeiro-caupi é cultivado em quase todas as microrregiões e ocupa o quarto lugar em área plantada no Nordeste (IBGE, 2008). A região de Pombal (PB) é delimitada por nove municípios produtores situados no Sertão Paraibano, onde a variedade mais utilizada é a Costela-de-vaca, que, tradicionalmente, tem sido obtida de plantios sucessivos realizados pelos próprios agricultores. A seleção das sementes não é realizada de forma criteriosa, contribuindo para a incidência de doenças, sobretudo aquelas ocasionadas por vírus, de difícil controle e responsáveis por grandes prejuízos.

Mundialmente, o feijoeiro-caupi pode ser infectado naturalmente por pelo menos 20 espécies virais (Hampton et al., 1997). Entre os principais vírus que prejudicam a cultura no Brasil, destaca-se Cowpea severe mosaic virus (CPSMV), pertencente ao gênero Comovirus. A ocorrência de isolados desse vírus provenientes de feijoeiro-caupi já foi relatada no Nordeste nos estados de Alagoas, Ceará, 
Piauí e Pernambuco, e um isolado foi obtido de plantas de Crotalaria paulinea L., proveniente do estado do Maranhão (Camarço et al., 2009). No estado do Paraná, esse vírus já foi verificado em plantas de feijoeiro-caupi e soja (Glycine $\max$ L.) (Bertacini et al., 1994).

De acordo com Pio-Ribeiro et al. (2005), os sintomas de mosaico ocasionados pelos potyvírus Cowpea aphidborne mosaic virus (CABMV) e Bean common mosaic virus (BCMV), estirpe "blackeye", são responsáveis por perdas elevadas do feijoeiro-caupi em casa de vegetação e no campo, dependendo da interação entre variedades e estirpe dos vírus, bem como da época de início da infecção. Além destas espécies virais, o feijoeiro-caupi pode ser infectado por Cucumber mosaic virus (CMV), pertencente ao gênero Cucumovirus, que, apesar de geralmente não causar significativa redução no crescimento da planta, possui maior gama de variedades suscetíveis e é capaz de interagir sinergisticamente com os vírus pertencentes ao gênero Potyvirus (Pio-Ribeiro et al., 2005).

A ocorrência de vírus do gênero Begomovirus infectando fabáceas no Brasil foi verificada em feijoeirocomum (Phaseolus vulgaris L.) com Bean golden mosaic virus (BGMV) (Faria \& Maxwell, 1999) e Sida micrantha mosaic virus (SiMMV) (Fernandes-Acioli et al., 2011). Em soja, além desses begomovírus, Fernandes et al. (2009) relataram a ocorrência de Okra mottle virus (OMoV), enquanto Assunção et al. (2006) detectaram a presença de begomovírus em plantas daninhas. No feijoeiro-caupi, entretanto, um isolado de Cowpea golden mosaic virus (CGMV) foi caracterizado em Goiânia (acesso no GenBank AF188708), e em outros países como a Índia (AY618902) e Nigéria (AF029217).

Todos esses vírus podem ocorrer isoladamente ou em infecções mistas que podem ocasionar alterações nos sintomas da doença (Lima et al., 2005; Kareem \& Taiwo, 2007), reduzindo significativamente o crescimento e o desenvolvimento e resultando em efeito severo da infecção do vírus no campo.

Estudos acerca da ocorrência dos vírus que infetam o feijoeiro-caupi são de grande importância para que se possam estabelecer as medidas mais adequadas de controle. Apesar da ocorrência de alguns isolados virais ter sido relatada anteriormente em feijoeiro-caupi cultivado em diferentes estados do Nordeste, não existem informações a respeito da incidência de viroses no feijoeiro-caupi cultivado no semiárido paraibano. Deste modo, este trabalho objetivou a realização de uma análise da ocorrência de viroses na cultura em campos de produção de municípios localizados no sertão paraibano e a identificação específica dos vírus de maior incidência na cultura entre as épocas seca e chuvosa.

Amostras foliares de plantas de feijoeiro-caupi da variedade Costela-de-vaca exibindo sintomas de mosaico e deformações foliares foram coletadas em campos de produção dos municípios de Bom Sucesso, Paulista e Pombal, nos meses de agosto a dezembro de 2009 e fevereiro a maio de 2010, períodos compreendidos entre a época seca e chuvosa, respectivamente. As amostras foliares coletadas foram enviadas para o Laboratório de Virologia Vegetal da Universidade Federal do Ceará, UFC, onde foram analisadas por "enzyme linked immunosorbent assay" (Elisa) indireto, contra anti-soros específicos para CABMV e CMV, técnica imuno-enzimática altamente específica e de elevada sensibilidade que tem sido usada na identificação e caracterização de espécies de vírus de planta (Voller et al., 1976; Clark \& Adams, 1977; Van Regenmortel \& Dubs 1993; Lima et al., 2012), inclusive das espécies que infetam o feijoeiro-caupi (Almeida \& Lima, 2001; Lima et al., 2005). As mesmas amostras foram, também, analisadas por dupla difusão em ágar contra anti-soro para CPSMV. Um total de 217 amostras coletadas foi analisado por sorologia, sendo que na época seca foram analisadas 134 amostras e, na época chuvosa, 83 amostras.

Parte das amostras coletadas na época chuvosa no município de Pombal apresentava sintomas de mosaicodourado; essas amostras foram submetidas à extração de DNA genômico realizada segundo o método descrito por Dellaporta et al. (1983) para posterior detecção de vírus do gênero Begomovirus por "Polymerase Chain Reaction" (PCR). O DNA extraído foi submetido a PCR utilizando-se o PCR SuperMix (Invitrogen, Carlsbarg, EUA) e os "primers" degenerados PAL1v1978/PAR1c496 para amplificação do fragmento de DNA A e PBL1v2040/ PCRc1 para amplificação do DNA B (Rojas et al., 1993). O DNA de cada mistura foi amplificado, mediante o seguinte ciclo para o DNA A: 3 min a $94^{\circ} \mathrm{C}$ seguido de 35 ciclos de desnaturação por $1 \mathrm{~min}$ a $94^{\circ} \mathrm{C}, 1 \mathrm{~min}$ a $50^{\circ} \mathrm{C}$ e $3 \mathrm{~min}$ a $72^{\circ} \mathrm{C}$, compreendendo, respectivamente, as etapas de desnaturação, anelamento e extensão; para a amplificação do DNA B utilizou-se 1 min a $55^{\circ} \mathrm{C}$ para a extensão.

Das 217 amostras coletadas, 159 estavam infectadas com vírus, sendo 36 somente com CPSMV, 56 com CABMV e 67 com infecção mista de CPSMV e CABMV. Na época seca, das 134 amostras analisadas foi constatada a presença de CPSMV e CABMV em 105 amostras em infecções simples e mistas nos três municípios avaliados. CMV não foi detectado em nenhuma das amostras analisadas (Tabela 1).

Os resultados das análises sorológicas na época seca indicaram que a ocorrência de CABMV predominou nos três municípios produtores analisados, sendo o município de Pombal o de maior incidência $(60,6 \%)$, o qual, coincidentemente, apresentou no campo predomínio de plantas com sintoma de mosaico-dourado. De outra parte, a ocorrência de CPSMV foi também verificada, embora em menores percentuais. Na época seca, CPSMV foi detectado durante todo o período, com a maior incidência no município de Bom Sucesso (17,64\%).

$\mathrm{Na}$ época chuvosa foram coletadas e analisadas 83 amostras provenientes das três localidades produtoras avaliadas na época seca. De acordo com os resultados obtidos na análise sorológica, CPSMV e CABMV foram detectados em 54 amostras $(65,06 \%)$ em infecções simples 
TABELA 1 - Incidência de Cowpea severe mosaic virus (CPSMV) e Cowpea aphid-borne mosaic virus (CABMV) e ausência de Cucumber mosaic virus (CMV) em plantios de feijoeiro-caupi (Vigna unguiculata) cultivados em época seca e chuvosa em três municípios do sertão paraibano

\begin{tabular}{|c|c|c|c|c|c|c|}
\hline \multirow[t]{2}{*}{ Município } & \multicolumn{2}{|c|}{ Número de amostras } & \multicolumn{4}{|c|}{$\begin{array}{l}\text { Número de plantas infectadas por vírus } \\
\text { (\% de infecção) }\end{array}$} \\
\hline & Coletadas & $\begin{array}{c}\text { Infectadas } \\
\text { (\% de infecção) }\end{array}$ & Infecção mista & CPSMV & CABMV & CMV \\
\hline \multicolumn{7}{|c|}{ Época seca } \\
\hline Bom Sucesso & 51 & $35(68,62)$ & $14(27,45)$ & $9(17,64)$ & $12(23,52)$ & - \\
\hline Paulista & 50 & $44(88,00)$ & $29(58,00)$ & $5(10,00)$ & $10(20,00)$ & - \\
\hline Pombal & 33 & $26(78,78)$ & $1(3,03)$ & $5(15,15)$ & $20(60,60)$ & - \\
\hline Sub-total & 134 & $105(78,36)$ & $44(32,84)$ & $19(14,17)$ & $42(31,33)$ & - \\
\hline \multicolumn{7}{|c|}{ Época chuvosa } \\
\hline Bom Sucesso & 20 & $18(90,00)$ & $8(40,00)$ & $9(45,00)$ & $1(5,00)$ & - \\
\hline Paulista & 28 & $24(85,71)$ & $15(53,57)$ & $2(7,14)$ & $7(25,00)$ & - \\
\hline Pombal & 35 & $12(34,28)$ & $0(0)$ & $6(17,14)$ & $6(17,14)$ & - \\
\hline Sub-total & 83 & $54(65,06)$ & $23(27,71)$ & $17(20,48)$ & $14(16,86)$ & - \\
\hline Total & 217 & $159(73,27)$ & $67(30,87)$ & $36(16,59)$ & $56(25,81)$ & - \\
\hline
\end{tabular}

e mistas. No entanto, como no período da seca, a presença de CMV não foi constatada (Tabela 1).

A ocorrência de CPSMV foi sorologicamente constatada em $20,48 \%$ do total das amostras, enquanto CABMV foi observado em 16,86\%. Ambos os vírus foram detectados em todas as localidades, entretanto, no município de Bom Sucesso, CPSMV apresentou a maior incidência (45\%), enquanto que CABMV ocorreu em menor incidência (5\%) (Tabela 1). A ocorrência de infecções mistas de CABMV e CPSMV foi observada em $32,84 \%$ das plantas analisadas na época seca e em $27,71 \%$ na época chuvosa (Tabela 1).

A ocorrência de vírus em feijoeiro-caupi já foi verificada em vários estados produtores circunvizinhos à Paraíba (Fernandes et al., 1993; Lima et al. 2005; PioRibeiro et al. 2005). Fernandes et al. (1993) observaram a incidência de viroses em plantios comerciais de feijoeirocaupi no Rio Grande do Norte. No presente levantamento, foi verificada a ocorrência de CPSMV e CABMV em duas épocas de cultivo, sendo que CABMV teve maior incidência na época seca, o que pode ser justificado pela alta população de afídeos comumente encontrados neste período do ano. CABMV é transmitido por várias espécies de afídeos, dentre as quais se destacam Aphis craccivora, A. fabae, A. gossypii, Myzus euphorbiae e M. persicae (Pio-Ribeiro et al., 2005). Entretanto, na época chuvosa, a incidência de CPSMV foi maior em relação à de CABMV, provavelmente, em razão da elevada população do inseto vetor no campo e da presença de plantas silvestres infectadas atuando como fontes de inóculo para CPSMV (Lima et al., 2005). Na época chuvosa foi constatada uma maior incidência de coleópteros, o que deve ter favorecido a maior incidência de CPSMV, considerando que o mesmo pode ser transmitido naturalmente por várias espécies da família
Chrysomelidae, destacando-se Cerotoma arcuata como a mais importante no Brasil (Lima et al., 2005; Pio-Ribeiro et al., 2005). Segundo Costa \& Batista (1979), CPSMV pode ser transmitido por dez espécies de coleópteros do gênero Cerotoma. De acordo com Freitas et al. (2002), os picos populacionais de espécies de coleópteros são registrados em épocas mais úmidas do ano.

A não ocorrência de CMV nos plantios visitados, nas diferentes épocas avaliadas pode ser explicada pela possível ausência de estirpe do vírus capaz de infectar o feijoeiro-caupi. De outra parte, a inibição ou interferência na transmissão de CMV pode ter ocorrido em função da presença de CABMV. Estudos realizados por Pinto (2003) constataram que a baixa incidência de CMV em plantas de abobrinha de moita (Cucurbita pepo L.) pode ter sido em decorrência da interferência dos vírus Papaya ringspot virus estirpe "watermelon" (PRSV-W) e Zucchini yellow mosaic virus (ZYMV) pertencentes ao gênero Potyvirus.

Infecções mistas entre CABMV e CPSMV ocorreram em todos os plantios dos municípios visitados nas duas épocas de cultivo. Por outro lado, Lima et al. (2005) relataram a infecção simultânea de CABMV e CMV reduzindo significativamente a produção de grãos em vários municípios do Ceará. De acordo com esses autores, normalmente, plantas com infecção mista, inclusive com a combinação CABMV e CPSMV, exibem sintomas mais severos do que aqueles observados em infecções isoladas, culminando em reduções significativas na altura da planta, peso e rendimento de grãos. Consequentemente, o crescimento, a produtividade e o teor de nutrientes das sementes são afetados (Taiwo \& Akinjogunla, 2006).

$\mathrm{O}$ sinergismo entre CABMV e CMV foram observados por Queiroz et al. (2010) na avaliação dos 
efeitos das infecções simples e mistas desses vírus em quatro genótipos de feijoeiro-caupi. Infecções múltiplas causadas por quatro a cinco vírus em feijoeiro-caupi foram também observadas por Shoyinka et al. (1997), sendo, no entanto, as infecções mistas causadas por dois vírus as mais prevalecentes. De acordo com Taiwo et al. (2007), infecção mista tem implicações biológicas, epidemiológicas e econômicas, pois podem ocorrer relações sinérgicas, levando a alterações nos sintomas da doença, alterações na movimentação sistêmica dos vírus e aumento ou diminuição da concentração dos vírus na planta.

A ocorrência de infecção com mais de uma espécie viral, normalmente, agrava o problema comprometendo o controle por variedades resistentes, tendo em vista que muitas cultivares identificadas ou desenvolvidas pela pesquisa com resistência individual a estirpes de CABMV e a CMV ou CPSMV não mantêm essa característica quando são infectadas por dois vírus (Lima et al., 2005). Visando à identificação de novas fontes de resistência simples e múltipla a vírus em feijoeiro-caupi, Lima et al. (2011) constataram que os genótipos Purple Knuckle Hull-55, MNC-03-731C-21 e CNCx284-66E mostram resistência a CABMV, mesmo após a inoculação de CMV.

Os resultados da presente análise revelaram elevados índices de infecção dupla nas amostras avaliadas, demonstrando que o possível efeito sinergístico entre vírus distintos reforça a importância do uso de variedades imunes ou de resistência consistente a, pelo menos, uma das espécies dos vírus, uma vez que até o momento não se sabe quais são os genes de resistência ou tolerância presentes na variedade de feijoeiro-caupi utilizada na região.

O uso dos "primers" PAL1v1978 e PAR1c496 para o componente de DNA A de vírus do gênero Begomovirus possibilitou a amplificação de um fragmento de aproximadamente $1,2 \mathrm{~Kb}$, enquanto que o resultado de PCR com os "primers" PBL1v2040 e PCRc1, para o componente B amplificou um fragmento em torno de $0,5 \mathrm{~Kb}$. A detecção molecular de vírus do gênero Begomovirus em amostras de feijoeiro-caupi coletadas no município de Pombal pode ser resultado da elevada incidência de Bemisia tabaci biótipo B na Região. PCR constitui uma técnica extremamente sensível e adequada para a detecção de vírus do gênero Begomovirus (Polston \& Anderson, 1997; Faria \& Maxwell, 1999); entretanto, estudos adicionais devem ser realizados para a identificação da espécie viral presente nas amostras.

Este estudo representa a primeira referência sobre a ocorrência de vírus em feijoeiro-caupi na região do sertão paraibano, sobretudo de CPSMV e CABMV detectados em campos de produção de todos os municípios amostrados em diferentes épocas de cultivo. Diante dos resultados constatados, torna-se imprescindível a adoção de estratégias de manejo e controle preventivo de vírus na cultura.

\section{REFERÊNCIAS BIBLIOGRÁFICAS}

Almeida AMR, Lima JAA (2001) Princípios e técnicas de diagnose aplicados em fitovirologia. Fortaleza CE. Sociedade Brasileira de Fitopatologia.

Assunção IP, Listik AF, Barros MCS, Amorim EPR, Silva SJC, Izael O, Ramalho-Neto CE, Lima, GSA (2006) Diversidade genética de begomovírus que infectam plantas invasoras na região nordeste. Planta Daninha 24:239-244.

Barros GB (2010) Identificação e caracterização de plantas de feijão-caupi obtidas por meio de retrocruzamentos resistentes aos vírus Cowpea severe mosaic virus (CPSMV) e Cowpea aphid borne mosaic virus (CABMV). Dissertação de Mestrado, Universidade Federal Rural do Rio de Janeiro. Seropédica RJ.

Bertacini PV, Almeida AMR, Chagas CM, Lima, JAA (1994) Ocorrência natural do vírus do mosaico severo do caupi infectando soja e caupi no Estado do Paraná. Fitopatologia Brasileira 19:271. (Resumo)

Camarço RFEA, Nascimento AKQ, Andrade EC, Lima JAA (2009) Biological, serological and molecular comparison between isolates of Cowpea severe mosaic virus. Tropical Plant Pathology 34:239-344.

Carvalho LM, Bueno VHP, Martinez RP (2002) Levantamento de afídeos alados em plantas hortícolas em Lavras-MG. Ciência e Agrotecnologia 26:523-532.

Costa CL, Batista MF (1979) Viroses transmitidas por coleópteros no Brasil. Fitopatologia Brasileira 4:177-179.

Dellaporta SL, Wood J, Hicks JB (1983) A plant DNA minipreparation: version II. Plant Molecular Biology Reporter 1:19-21.

Faria JC, Maxwell DP (1999) Variability in geminivirus isolates associated with Phaseolus spp. in Brazil. Phytopathology 89:262268.

Fernandes JB, Holanda JS, Souza NM, Chagas MCM (1993) A adaptabilidade ambiental e incidência de viroses em cultivares de caupi no Rio Grande do Norte. Pesquisa Agropecuária Brasileira 28:33-37.

Fernandes FR (2009) Caracterização molecular e biológica de begomovírus de soja (Glycine Max) e leiteiro (Euphorbia heterophylla) e resistência a vírus mediada por RNA indiferente em plantas transgênicas de soja. Tese de Doutorado, Universidade Federal de Viçosa. Viçosa MG.

Fernandes FR, Cruz ARR, Faria JC, Zerbini FM, Aragão FJL (2009) Three distinct begomoviruses associated with soybean in central Brazil. Archives of Virology 154:1567-1570.

Fernandes-Acioli NAN, Pereira-Carvalho RC, Fontenele RS, Lacorte C, Ribeiro SG, Fonseca MEN, Boiteux LS (2011) First report of Sida micrantha mosaic virus in Phaseolus vulgaris in Brazil. Plant Disease 95:1196.

Freitas FA, Zanuncio TV, Lacerda MC, Zanuncio JC (2002) Fauna de Coleoptera coletada com armadilhas luminosas em plantio de Eucalyptus grandis em Santa Bárbara, Minas Gerais. Revista Árvore 26:505-511.

Hampton RO, Thottappily G, Rossel HW (1997) Viral diseases of cowpea and their control by resistance-confering genes. In: Singh BB, Mohan Raj DR, Dashiell KE, Jackai LEN (Eds.) Advances in 
cowpea research. Ibadan Nigéria. IITA, JIRCAS. pp. 159-175.

IBGE - Instituto Brasileiro de Geografia e Estatística (2008) Sistema IBGE de recuperação automática - SIDRA. Disponível em: <http://www.sidra.ibge.gov.br>. Acesso em: abril de 2012.

Kareem KT, Taiwo MA (2007) Interactions of viruses in cowpea: Effects on growth and yield parameters. Virology Journal 4:15.

Koenig R (1981) Indirect ELISA methods for the broad specificity detection of plant viruses. Journal of General Virology 55:53-62.

Lima JAA, Nascimento AKQ, Radaelli P, Purcifull DE (2012) Serology applied to plant virology. In: Molish-Al-Moslih M (Ed.) Serological diagnosis of certain human, animal and plant diseases. Rijeka Croácia. InTech. pp. 71-94.

Lima JAA, Sittolin IM, Lima RCA (2005) Diagnose e estratégias de controle de doenças ocasionadas por vírus. In: Freire Filho FR, Lima JAA, Ribeiro VQ. (Eds.) Feijão-caupi: Avanços Tecnológicos. Brasília DF. Embrapa Informação Tecnológica. pp. 404-459.

Lima JAA, Silva AKF, Aragão ML, Ferreira, NRA, Teófilo, EM (2011) Simple and multiple resistances to viruses in cowpea genotypes. Pesquisa Agropecuária Brasileira 46:1432-1438.

Lourenço A, Pinto J (1988) Os níveis populacionais de afídeos nas Searas do Alentejo anos de 1981 e 1982. Agronomia Lusitana 43:81-87.

Nogueira MSR, Oliveira CRR, Sittolin IM, Barros GB, Freire Filho FR, Brioso PST (2009) Incorporação de genes de resistência a vírus em cultivares elites de feijão-caupi. In: $2^{\circ}$ Congresso Nacional de Feijão-Caupi, Anais... Belém PA. Embrapa MeioNorte.

Pinto ZV (2003) Efeito da origem dos isolados do Cucumber mosaic virus (CMV) e da presença de dois potyvirus na transmissão do CMV para abobrinha de moita por meio de duas espécies de afídeos. Dissertação de Mestrado, Universidade de São Paulo/ Esalq. Piracicaba SP.
Pio-Ribeiro G, Assis Filho FM, Andrade G. P (2005) Doenças do caupi (Vigna unguiculata). In: Kimati H, Amorim L, Rezende JAM, Bergamin Filho A, Camargo LEA (Eds.) Manual de Fitopatologia. Doenças das Plantas Cultivadas. São Paulo SP. Agronômica Ceres. pp. 215-222.

Polston JE, Anderson PK (1997) The emergence of whiteflytransmitted geminiviruses in tomato in the Western Hemisphere. Plant Disease 81:1358-1369.

Queiroz JVJ, Pio-Ribeiro G, Andrade GP, Nicolini C (2010) Infecções simples e mistas de Cowpea aphid-borne mosaic virus e Cucumber mosaic virus em diferentes genótipos de feijão-caupi. X Jornada de Ensino, Pesquisa e Extensão da UFRPE - JEPEX, Anais... Recife PE. UFRPE.

Rocha MM, Lima JAA, Freire Filho FR, Rosal CJS, Lopes ACA (2003) Resistência de genótipos de caupi (Vigna unguiculata L. Walp.) de tegumento branco a isolados de vírus das famílias Bromoviridae, Comoviridae e Potyviridae. Ciência Rural 8:8592.

Rojas MR, Gilbertson RL, Russel DR, Maxwell DP (1993) Use of degenerate primers in the polymerase chain reaction to detect whitefly-transmitted geminiviruses. Plant Disease 77:340-347.

Shoyinka SA, Thottappilly G, Adebayo GG, Anno-Nyako FO (1997) Survey on cowpea virus incidence and distribution in Nigeria. International Journal of Pest Management 43:127-132.

Taiwo MA, Kareem KT, Nsa IY, Hughes J (2007) Cowpea viruses: Effect of single and mixed infections on symptomatology and virus concentration. Virology Journal 4:95.

Taiwo MA, Akinjogunla OJ (2006) Cowpea viruses: Quantitative and qualitative effects of single and mixed viral infections. African Journal of Biotechnology 5:1749-1756.

Van Regenmortel MHV, Dubs MC (1993) Serological procedures. In: Matthews REF (Ed.) Diagnosis of plant virus diseases. Boca Raton FL. CRC Press. pp. 159-214. 